\title{
Optimization of in vitro culture and transfection condition of bovine primary spermatogonial stem cells
}

\author{
A. Jafarnejad ${ }^{1}$, M. Aminafshar ${ }^{1 \#}$, M. Zandi ${ }^{2}$, M. R. Sanjabi ${ }^{2}$ \& N. Emamjomeh Kashan ${ }^{1}$ \\ ${ }^{1}$ Department of Animal Science, Faculty of Agriculture and Natural Resources, Science and Research Branch, \\ Islamic Azad University, Tehran, Iran \\ ${ }^{2}$ Department of Agriculture, Iranian Research Organization for Science and Technology (IROST), \\ P. O. Box 33535111, Tehran, Iran
}

(Received 6 May 2017; Accepted 7 August 2017; First published online 17 November 2017)

\author{
Copyright resides with the authors in terms of the Creative Commons Attribution 4.0 South African License. \\ See: http://creativecommons.org/licenses/by/4.0/za \\ Condition of use: The user may copy, distribute, transmit and adapt the work, but must recognize the authors and the South \\ African Journal of Animal Science.
}

\begin{abstract}
The present study aimed to optimize the in vitro culture and transfection efficiency of bovine primary spermatogonial stem cells (SSCs). To this end, SSCs were obtained from newborn Holstein bull calves by two-step enzymatic digestion. After enrichment and culture, SSCs were characterized by using alkaline phosphatase (AP) staining and expression of vasa and thy 1 genes as specific bovine SSC markers. To evaluate the effect of antioxidants on vitality, colony formation, and the expression of pro- and anti-apoptotic genes of bovine SSCs, various concentrations of vitamin C (5, 10, 25 and $50 \mu \mathrm{g} / \mathrm{mL}$ ) and Trolox (a water soluble $\alpha$-tocopherol analogue) $(12.5,25,50$ and $100 \mu \mathrm{g} / \mathrm{mL}$ ) were added to the SSC culture medium. The results showed that SSCs treated with $50 \mu \mathrm{g} / \mathrm{mL}$ of vitamin C or $25 \mu \mathrm{g} / \mathrm{mL}$ of Trolox individually could increase cell viability and colony formation significantly in comparison with other concentrations and the control group. Additionally, the expressions of bax (as a pro-apoptotic gene) and bcl2 (as an anti-apoptotic gene) were significantly lower and higher than the control group, respectively. To optimize the transfection condition, the effective dosages of vitamin $C$ or Trolox, with various concentrations of two transfection reagents (X-tremeGENE HP and Turbofect) and DNA, at day 8 of culture, were studied. Results showed that $1 \mu \mathrm{l} \mathrm{X-tremeGENE} \mathrm{HP} \mathrm{or} 0.5 \mu \mathrm{l}$ Turbofect and $2 \mu \mathrm{g}$ of DNA are the best concentrations for transfecting SSCs. However, X-tremeGENE HP expressed more potential for transfecting SSCs in comparison with Turbofect. Besides, no difference was observed between the use of defined doses of vitamin C or Trolox.
\end{abstract}

Keywords: Apoptosis, gene transfer, primary cells, viability, vitamin C, Trolox

\# Corresponding author: aminafshar@gmail.com

\section{Introduction}

Since the 1980s, when transgenic mice were first generated (Gordon et al., 1980), transgenesis has been used widely to produce genetically modified animals (Niu \& Liang, 2008). Along with other gene transfer techniques, there has been cumulative interest in the possibilities of using the male germline to create transgenic animals (Aponte, 2009). This approach has innumerable advantages in farm animals, because a single male would be capable of generating a wide range of transgenic progenies (Olive \& Cuzin, 2005) and, in particular, when one considers the long generation interval in bovine species, this technique could shorten the time required to obtain transgenic cattle (Aponte \& de Rooij, 2008). Meanwhile, SSCs have attracted much attention owing to their unique properties, such as high self-renewal and differentiation potential, pluripotency, and ability to transfer genetic information to offspring (Miao, 2011). Spermatogonial stem cell-based methods of transferring genes to new generations provide a promising future in the field of animal science to accelerate the generation of transgenic animals more rapidly and effectively (Wang et al., 2014). However, to gain these desirable outcomes, some difficulties need to be surmounted (Kim et al., 1997).

One of the problems is transferring genes to primary stem cells in vitro (Hamm et al., 2002). Cells in their early stages of development in vitro are so important because, from a biological point of view, they are broadly similar to the in vivo condition (Gresch et al., 2004). Nearly all of the prevalent and efficacious 
transfection procedures for transfecting cell lines are unable to transfect primary cells (Hamm et al., 2002). Viral strategies have been considered unsafe and time consuming. Among non-viral procedures, transfection efficiency of physical methods is low. Additionally, the efficiency of lipofection as the major chemical approach is low (Gresch et al., 2004). The majority of attempts have been on human primary cells and in some cell types mortality after transfection has been reported to be relatively high (Hamm et al., 2002). It seems to be important to develop and introduce a highly efficient and specific method for transfecting bovine primary SSCs with the capability of preserving the viability of cells at an optimal level.

Another obstacle to the use of SSCs as a vehicle for gene transfer, especially in domestic animals, is the absence of an ideal culture system that can support the expansion and maintenance of SSCs (Wang et al., 2014). Therefore, the development of techniques to culture SSCs seems to be important (Aponte \& de Rooij, 2008). Since 1998, when the first SSC culture was developed by Nagano et al. (1998), great progress has been made in the development of culture systems for SSCs (Aponte, 2009). Nevertheless, even the most optimized culture medium in vitro is in a static condition, which is different from the in vivo state (Wang et al., 2014), and to provide conditions relatively similar to the natural niche, all harmful effects to the SSC life cycle should be taken into account. Among them, oxidative stress and apoptosis are known to be the most common injuries to SSCs (Kushki et al., 2015).

Oxidative stress related to the generation of reactive oxygen species (ROS) is associated with cell proliferation, differentiation, and apoptosis in various systems (Shi et al., 2014). It occurs to cells both in vivo and in vitro from exposure to free radicals (Moreira et al., 2010). However, there is evidence that in vitro cultured cells show higher ROS concentration (Wang et al., 2014). Although low concentrations of ROS are crucial to the acquisition of fertilizing ability (Moreira et al., 2010), high levels of ROS may culminate in cellular injury and apoptosis, owing to damage to the membrane, lysis of cells, organelle dysfunction, and calcium dyshomeostasis (Kushki et al., 2015). Therefore, it is necessary to maintain appropriate ROS levels in SSC culture media (Wang et al., 2014).

Recent studies have demonstrated that supplementing the culture medium with an appropriate amount of vitamin C can enhance the efficiency of induced pluripotent stem cells (Wang et al., 2014). Vitamin $C$ is a natural compound that is supplemented to culture media to reduce the production of ROS to an appropriate level. As a result, it protects cells from oxidative damage and apoptosis by inhibiting apoptotic signals and activating anti-apoptotic signals in vitro (Hu et al., 2012).

On the other hand, vitamin $E$ has been regarded as a natural antioxidant that reacts with soluble free radicals in lipid membranes (Moreira et al., 2010). Derivatives of the vitamin E family are shown to have significant effects on cell signalling, regulation of gene expression, inflammation, cell proliferation, apoptosis, and scavenging of ROS and reactive nitrogen species (Aliakbari et al., 2016).

Therefore, in the present study, the authors' first objective was to investigate the effects of vitamin C and Trolox at various levels on bovine SSC viability and expression of apoptosis-associated genes in order to develop and propose an optimized culture media. The second objective was to optimize the transfection condition of primary SSCs.

\section{Materials and methods}

All experimental procedures on animals were conducted in accordance with the Australian Code of Practice for the Care and Use of Animals for Scientific Purposes. Unless otherwise mentioned, all chemicals and reagents were purchased from Sigma (Sigma Aldrich, St. Louis, MO, USA) and media were obtained from Gibco (Life Technologies, Rockville, MD, USA).

Testes of six relatively newborn Holstein bull calves, as donors of testicular tissues, were surgically removed and transported to the laboratory within two hours to isolate SSCs. After washing with Dulbecco's phosphate-buffered saline (DPBS) supplemented with $100 \mathrm{IU} / \mathrm{mL}$ penicillin and cutting the tunica albuginea, small fragments of parenchyma were taken to digest using a two-step enzymatic treatment as described by Izadyar et al. (2002) with minor modifications. Briefly, for the first enzymatic digestion, minced testicular tissues suspended in Dulbecco's modified eagle medium (DMEM), containing $1 \mathrm{mg} / \mathrm{mL}$ collagenase, 1 $\mathrm{mg} / \mathrm{mL}$ trypsin (Invitrogen), $1 \mathrm{mg} / \mathrm{mL}$ hyaluronidase type II, and $5 \mathrm{mg} / \mathrm{mL}$ DNase I suspension, were incubated at $37.5^{\circ} \mathrm{C}$ for 45 minutes in a shaker incubator operated at $200 \mathrm{rpm}$. Then the dispersed tissue was collected and centrifuged at $1000 \mathrm{rpm}$ for two minutes. After the first enzymatic digestion, supernatant containing the interstitial cells was discarded. For the second enzymatic digestion, the remaining pellets containing testis fragments were re-suspended in DMEM containing $1 \mathrm{mg} / \mathrm{mL}$ collagenase, $1 \mathrm{mg} / \mathrm{mL}$ hyaluronidase and $5 \mathrm{\mu g} / \mathrm{mL}$ DNase, and incubated in a shaker incubator $(200 \mathrm{cycles} / \mathrm{min})$ for 30 minutes at $37.5^{\circ} \mathrm{C}$. Cells were separated from the remaining tubule fragments by centrifugation at $1000 \mathrm{rpm}$ for two minutes.

To enrich SSCs, differential plating was used to eliminate the somatic cells (myoid and Sertoli cells). First, dishes coated with lectin-bovine serum albumin (BSA) were prepared. Briefly, petri dishes were coated 
with a solution of $5 \mu \mathrm{g} / \mathrm{mL}$ Datura starmonium agglutinin lectin in DPBS. The dishes were kept at $37{ }^{\circ} \mathrm{C}$ for two hours. For coating BSA, dishes were washed three times with DMEM containing $0.6 \%$ BSA and kept at room temperature for another two hours. The supernatant was filtered with the help of an $80 \mu \mathrm{m}$ nylon net filter and then a $60 \mu \mathrm{m}$ filter. The filtered cells were then transferred to $70 \mathrm{~mm}$ petri dishes coated with lectinBSA. To enable most of contaminating cells to become attached to the lectin-BSA, the suspension, containing the Sertoli and germ cells, was incubated between 5 and 6 hours at $37^{\circ} \mathrm{C}$ in a $\mathrm{CO}_{2}$ incubator with $5 \% \mathrm{CO}_{2}$ in air. After that, unattached cells in the remaining medium, which was expected to contain SSCs, were collected and transferred to a $15 \mathrm{~mL}$ tube and centrifuged for 5 minutes at $1000 \mathrm{rpm}$. At the end, after discarding the supernatant, the remnant of the cells in pellet form were re-suspended in DMEM and subjected to percoll density gradient cell separation for further purification, as described by Van Pelt et al. (1996).

The cells, which adhered firmly to the bottom of lectin-coated dishes, were revitalized with fresh DMEM supplemented with $10 \%$ FBS and incubated in a $\mathrm{CO}_{2}$ incubator with $5 \% \mathrm{CO}_{2}$ in air at $37{ }^{\circ} \mathrm{C}$ for $2-3$ days to enable the cells - which were expected to be primarily Sertoli cells - to grow and form a confluent monolayer. For propagation, the cells were sub-cultured in a $25 \mathrm{~cm}$ culture flask after being disaggregated with $0.25 \%$ trypsin-EDTA. To prepare a feeder layer, Sertoli cells were inactivated by treatment with 10 $\mu \mathrm{g} / \mathrm{mL}$ mitomycin-C for three hours and were subsequently washed five times with DPBS and finally with DMEM supplemented with $10 \%$ FBS.

The isolated SSCs were cultured on the Sertoli cells feeder layer in $70 \mathrm{~mm}$ dishes containing 10 $\mu \mathrm{g} / \mathrm{mL}$ glial cell line-derived neurotrophic (GDNF) and in the presence of various concentrations of vitamin $\mathrm{C}$ and Trolox and then incubated in a $\mathrm{CO}_{2}$ incubator with $5 \% \mathrm{CO}_{2}$ in air at $37{ }^{\circ} \mathrm{C}$. The culture medium was replaced every third day with the DMEM medium supplemented with 10\% FBS. SSC colonies were observed after seven days.

Cell viability was measured by the MMT assay. MTT or 3-(4,5-dimethyl-2-thiazolyl)-2, 5-diphenyl-2Htetrazolium bromide (MTT; Sigma, Germany), as a quantitative colorimetric assay for detecting live cells, is a yellow tetrazolium salt, which is reduced to dark blue formazan after incubation with living cells (Mosmann, 1983).

For characterization of SSCs, AP staining and expression of vasa and thy1 genes were utilized. For AP staining, SSC colonies were washed twice with DPBS and then stained using an AP kit as per the manufacturer's protocol.

The expression of the SSCs markers was studied by reverse transcription polymerase chain reaction (RT-PCR). Total RNA was extracted by Trizol reagent (Invitrogen) and subsequently treated with DNase (Ambion) to restrain DNA contamination. Isolated RNA was reverse-transcribed to CDNA using oligo(d)T priming and Maloney murine leukaemia virus (M-MLV) reverse transcriptase. PCR was set up in a final volume of $25 \mu \mathrm{L}$ with 10X PCR buffer (SinaClon), $10 \mathrm{mM}$ dNTPs (SinaClon), 1.0U GoTaq DNA polymerase (SinaClon), and $10 \mu \mathrm{M}$ each of forward and reverse primers. The PCR program was started with an initial melting cycle at $94{ }^{\circ} \mathrm{C}$ for three minutes to activate the polymerase, followed by 45 amplification cycles of denaturation at $94^{\circ} \mathrm{C}$ for 30 seconds, annealing specific primers at $58.5^{\circ} \mathrm{C}$ for 30 and $72{ }^{\circ} \mathrm{C}$ for a 30 -second extension. The reactions were ended with a final extension at $72^{\circ} \mathrm{C}$ for 10 minutes.

The changes in expression of apoptotic-related genes were studied by real-time PCR. The real-time PCR program was started with an initial melting cycle at $94^{\circ} \mathrm{C}$ for 15 minutes to activate the polymerase, followed by 40 amplification cycles of denaturation at $95^{\circ} \mathrm{C}$ for 10 seconds, annealing specific primers at 62 ${ }^{\circ} \mathrm{C}$ for 15 seconds, and $72{ }^{\circ} \mathrm{C}$ for a 20 -second extension. The reactions were ended with a final extension at $72{ }^{\circ} \mathrm{C}$ for five minutes. The housekeeping gene $\beta$-actin was used as an internal standard in all experiments. The primers used for both reverse transcription PCR and real-time PCR are listed in Table 1.

The enhanced green fluorescent protein (EGFP) plasmid construction (pEGFPN1, 5.4 kb) used in this experiment contained the human CMV immediate early promoter and the enhanced GFP gene. Plasmids were extracted using Plasmid Mega Kit (Qiagen) and then linearized using the Stu1 restriction enzyme (Takara) following the manufacturer's instructions. Ultimately, digestion efficiency was confirmed by $1 \%$ agarose gel electrophoresis.

Various concentrations of DNA $(1,2$ and $4 \mu \mathrm{g})$ and X-tremeGENE HP and Turbofect as transfection reagents $(0.5,1$ and $2 \mu \mathrm{l})$ were diluted in $50 \mu \mathrm{l}$ of transfection medium separately, and incubated for 5 minutes at room temperature. Then, the diluted DNA was added to diluted X-tremeGENE HP or Turbofect (total volume $100 \mu \mathrm{l}$ for each) and incubated for $20 \mathrm{~min}$ at room temperature. The $100 \mu \mathrm{l}$ of complexes was added to wells containing $1 \times 10^{6} / \mathrm{ml}$ spermatozoa and mixed gently by rocking the plate back and forth. The cells were then incubated at $37^{\circ} \mathrm{C}$ in a $\mathrm{CO}_{2}$ incubator for 24 hours prior to testing for transgene expression by fluorescence microscopy (Nikon Eclipse TE300). 
Table 1 List of primer sequences used for different polymerase chain reactions

\begin{tabular}{|c|c|c|c|c|}
\hline Gene & Sequence & $\begin{array}{c}\text { Annealing } \\
\text { temperature }\end{array}$ & $\begin{array}{l}\text { Base } \\
\text { pairs }\end{array}$ & $\begin{array}{c}\text { Accession } \\
\text { number }\end{array}$ \\
\hline vasa & $\begin{array}{l}\text { F- 5' TCTTGGAGATTTCCGCTG 3' } \\
\text { R- 5' GGCTGTGCTAACTGGCTA 3' }\end{array}$ & 58.5 & 219 & JX437186.1 \\
\hline thy 1 & $\begin{array}{c}\text { F- 5' CGTCTCCAATAAGGATGTC } 3^{\prime} \\
\text { R- 5' } \\
\text { ' }\end{array}$ & 58.5 & 146 & NM_001034765.1 \\
\hline$b c / 2$ & $\begin{array}{l}\text { F- 5' GATGACTTCTCTCGGCGCTA } 3^{\prime} \\
\text { R- 5' GACCCCTCCGAACTCAAAGA } 3^{\prime}\end{array}$ & 62 & 165 & AY547260.1 \\
\hline bax & $\begin{array}{l}\text { 3' F- 5' GTGAGACCTCTAACCCCACC } \\
\text { 3' R- 5' GGTCAGAGGTCATGAGGAGG }\end{array}$ & 62 & 175 & GU731063.1 \\
\hline$\beta$-actin & $\begin{array}{l}\text { F- 5' ACCCAGCACGATGAAGATCA 3' } \\
\text { R- 5' GTAACGCAGCTAACAGTCCG 3' }\end{array}$ & 62 & 187 & U39357.1 \\
\hline
\end{tabular}

To attain the objectives of this study, two experimental designs were conducted. The first experiment was carried out to verify the optimal concentration among individual and combined dosages of vitamin $\mathrm{C}(5$, 10,25 and $50 \mu \mathrm{g} / \mathrm{mL}$ ) and Trolox $(12.5,25,50$ and $100 \mu \mathrm{g} / \mathrm{mL})$ on SSC culture media. For this reason, viability, colony formation and expression of bax and $b c / 2$ genes were studied. The second experiment was performed to optimize the transfection condition of SSCs. For this reason, at day 8 of culture, in the presence of defined and optimum concentrations of vitamins C or Trolox, SSCs were transfected using exogenous DNA in 1, 2 and $4 \mu \mathrm{g}$ concentrations and with the help of X-tremeGENE HP or Turbofect as transfection reagents in $0.5,1$ and $2 \mu \mathrm{l}$ concentrations for $100 \mu \mathrm{l}$ media.

Data were analysed with a statistical software program (SPSS 16, IBM, USA). After a normality test, comparisons between multiple numeric datasets were performed using one-way ANOVA followed by Duncan's multiple-range test. Results were expressed as mean \pm SEM and statistical significance was accepted at $P<0.05$.

\section{Results}

The SSCs were isolated through two-time enzymatic digestion and SSC colonies were formed seven days after culture. Vasa and thy 1 genes were detected as specific markers in these colonies (Figure 1), and were positive for AP staining (Figure 2).

The main purpose of the first experiment was to evaluate the effectiveness of various concentrations of vitamin C and Trolox alone or in combination on the vitality of bovine SSCs, colony formation and the expression of pro- and anti-apoptotic gens. The results from the MTT assay demonstrated that the viability of SSCs in cultures that were separately supplemented with $50 \mu \mathrm{g} / \mathrm{mL}$ of vitamin C or $25 \mu \mathrm{g} / \mathrm{mL}$ of Trolox was higher $(P<0.05)$ than the control group (Figure 3). Likewise, under the same concentrations of vitamin $\mathrm{C}$ and Trolox, colony formation was increased $(P<0.05)$ after seven days of culture (Figure 5$)$. Moreover, the levels of the apoptosis regulator bax and anti-apoptotic bcl2 expression were lower and higher $(P<0.05)$ than the control group, respectively (Figure 6). The synergistic effects of effective concentrations of vitamin $C$ and Trolox were also investigated by MTT assay. Although in some cases, cell viability and colony formation in cultures containing the combined additions of vitamin $C$ and Trolox were higher $(P<0.05)$ than the control group, the results revealed that the combination of vitamin $C$ and Trolox was not as effective as using them alone (Figure 4). Similarly, the expressions of pro- and anti-apoptotic genes in cultures treated with combined concentrations of vitamin $\mathrm{C}$ and Trolox were not significant compared with the control group.

The second experiment aimed at determining the optimal transfection conditions of primary SSCs using defined effective and optimum concentrations of vitamin C and Trolox on SSCs culture media, along with various concentrations of two transfection reagents and DNA at day 8 of culture. The results showed that $1 \mu \mathrm{l} \mathrm{X-tremeGENE} \mathrm{HP} \mathrm{or} 0.5 \mu \mathrm{l}$ Turbofect and $2 \mu \mathrm{g}$ of DNA were the best concentrations for transfection of SSCs. However, transfection of SSC colonies resulted in higher efficiency (Figure 7), when X-tremeGENE HP was used (around $70 \%$ and $40 \%$ for X-tremeGENE HP and Turbofect, respectively). Moreover, no difference was observed when SSCs cultured under $25 \mu \mathrm{l} / \mathrm{ml}$ Trolox or $50 \mu \mathrm{g} / \mathrm{ml}$ vitamin C alone. 


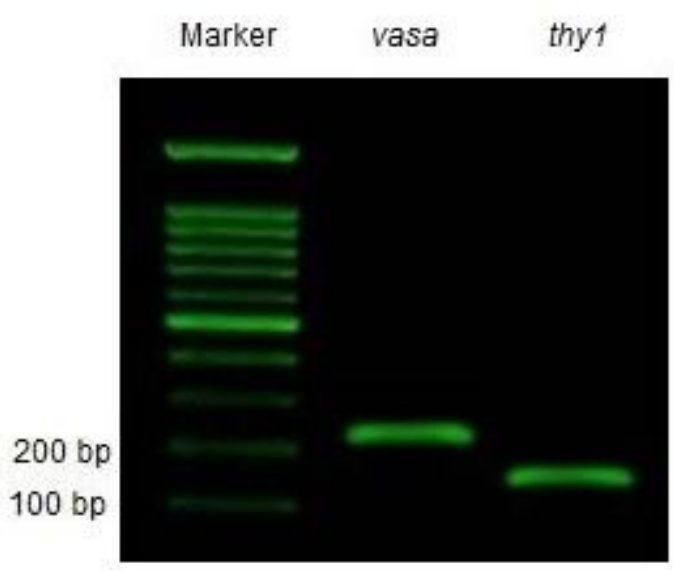

Figure 1 Expression of vasa and thy 1 genes

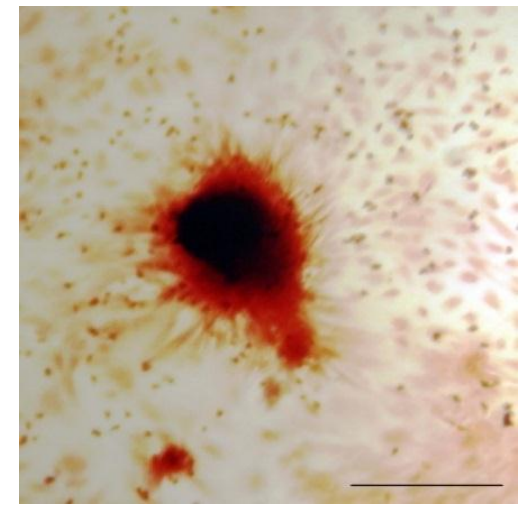

Figure 2 Alkaline phosphatase staining 7 days after culture $($ Bar $=1 \mathrm{~mm})$

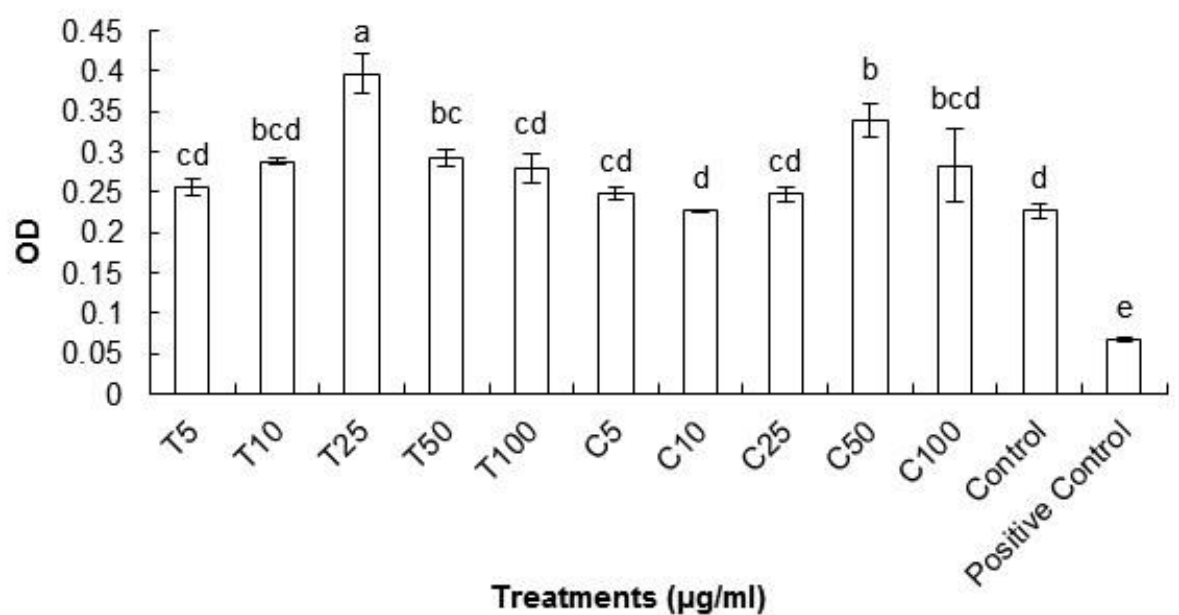

Figure 3 Effect of vitamin C and Trolox on viability of spermatogonial stem cells, T: Trolox, C: vitamin C

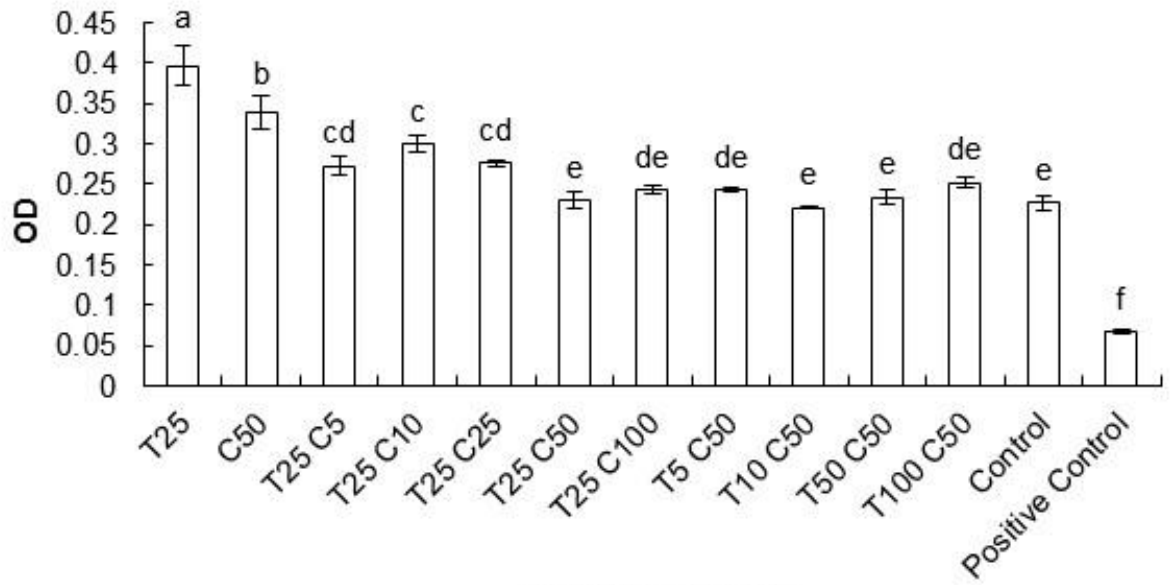

Treatments $(\mu \mathrm{g} / \mathrm{ml})$

Figure 4 Effect of effective concentration of vitamin $\mathrm{C}$ and Trolox, alone and in combination, on viability of spermatogonial stem cells, T: Trolox, C: vitamin C 


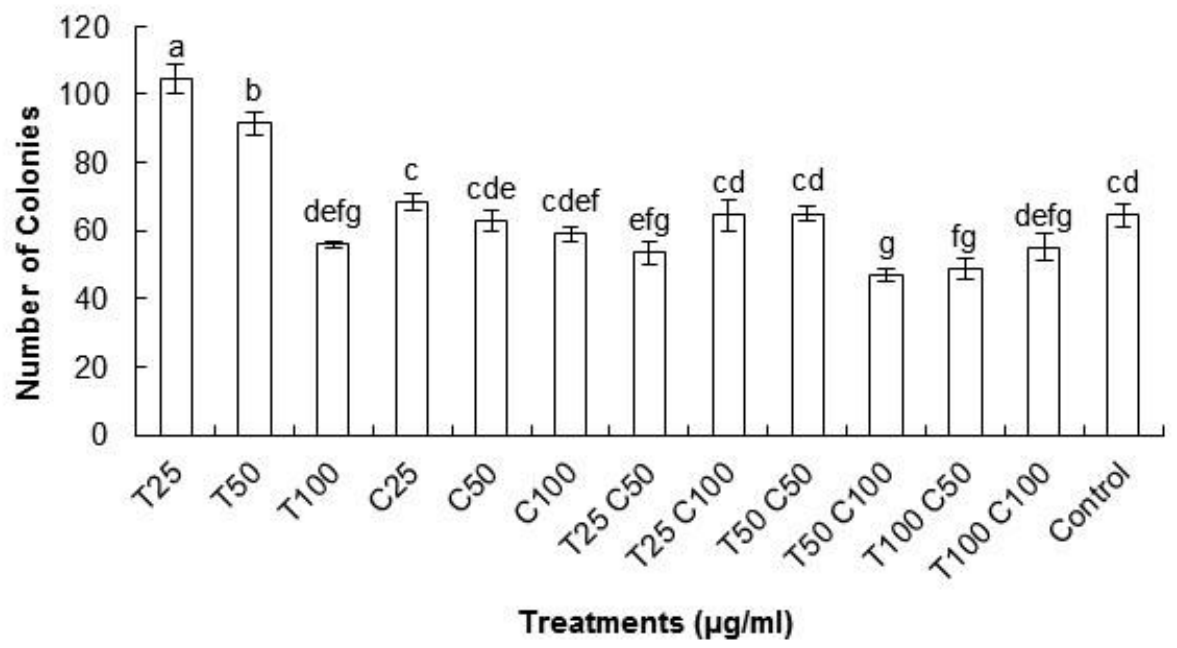

Figure 5 Effect of effective concentration of vitamin $C$ and Trolox, alone and in combination, on spermatogonial stem cells colony formation, T: Trolox, C: vitamin C
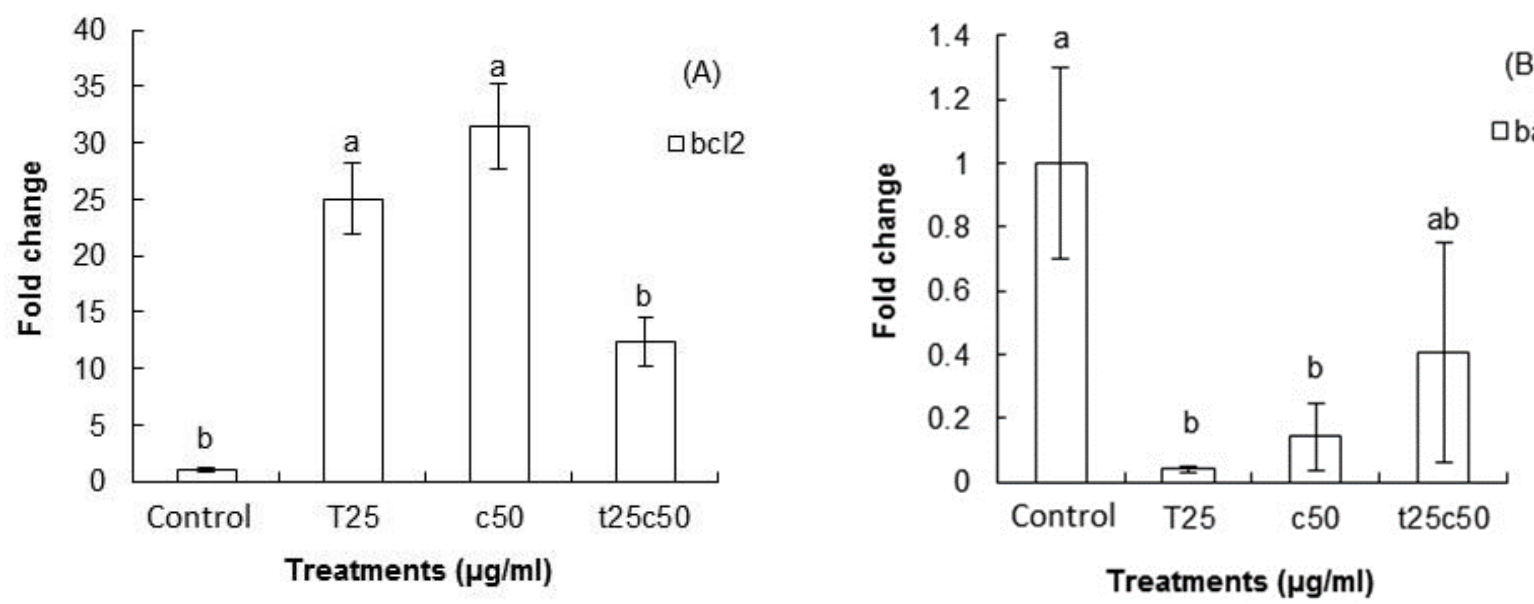

Figure 6 Effect of effective concentration of vitamin $\mathrm{C}$ and Trolox, alone and in combination, on expression of $b c / 2$ (A) and bax (B) on spermatogonial stem cells, T: Trolox, C: vitamin C

\section{Discussion}

In the current study, SSCs were extracted using two-step enzymatic digestion and, after enrichment, cultured on Sertoli cells as feeder layer. Unlike somatic testicular cells forming a confluent monolayer of cells, SSCs appeared in colony form after seven days of culture. The colony of SSCs showed AP activity and expression of bovine SSCs markers (vasa and thy1).

Although SSCs can be maintained and withstand long periods in vitro conditions (Li et al., 2005), many factors can affect cell vitality during culture. The viability of cells during culture has a downward trend and decline after three days (Liu et al., 2011). This reduction in the survival rate of SSCs may be caused by the accumulation of toxic products of metabolism and ROS formation (Aliakbari et al., 2017). High levels of ROS production can increase the expression level of ROS-related genes such as bax and the proportion of the pro-apoptotic to anti-apoptotic genes markedly determines cell fate (Hu et al., 2012). In cells that are subject to apoptosis, bax, as a pro-apoptotic protein, forms pores on the mitochondrial membrane and expels cytochrome $\mathrm{C}$ from mitochondria to trigger the formation of a large protein complex called apoptosome. Apoptosome will then induce the activation of a caspase proteolytic cascade, which will cleave and destroy cellular proteins and DNA (Chandar \& Viselli, 2010). In return, bcl-2, as an anti-apoptotic protein, can block apoptosis by binding pro-apoptotic proteins such as bax or by preventing the release of cytochrome $\mathrm{C}$ from the mitochondrial membrane (lannolo et al., 2007). Using vitamin C and Trolox in the current study could increase the expression of $b c / 2$, and decrease the expression of bax. 

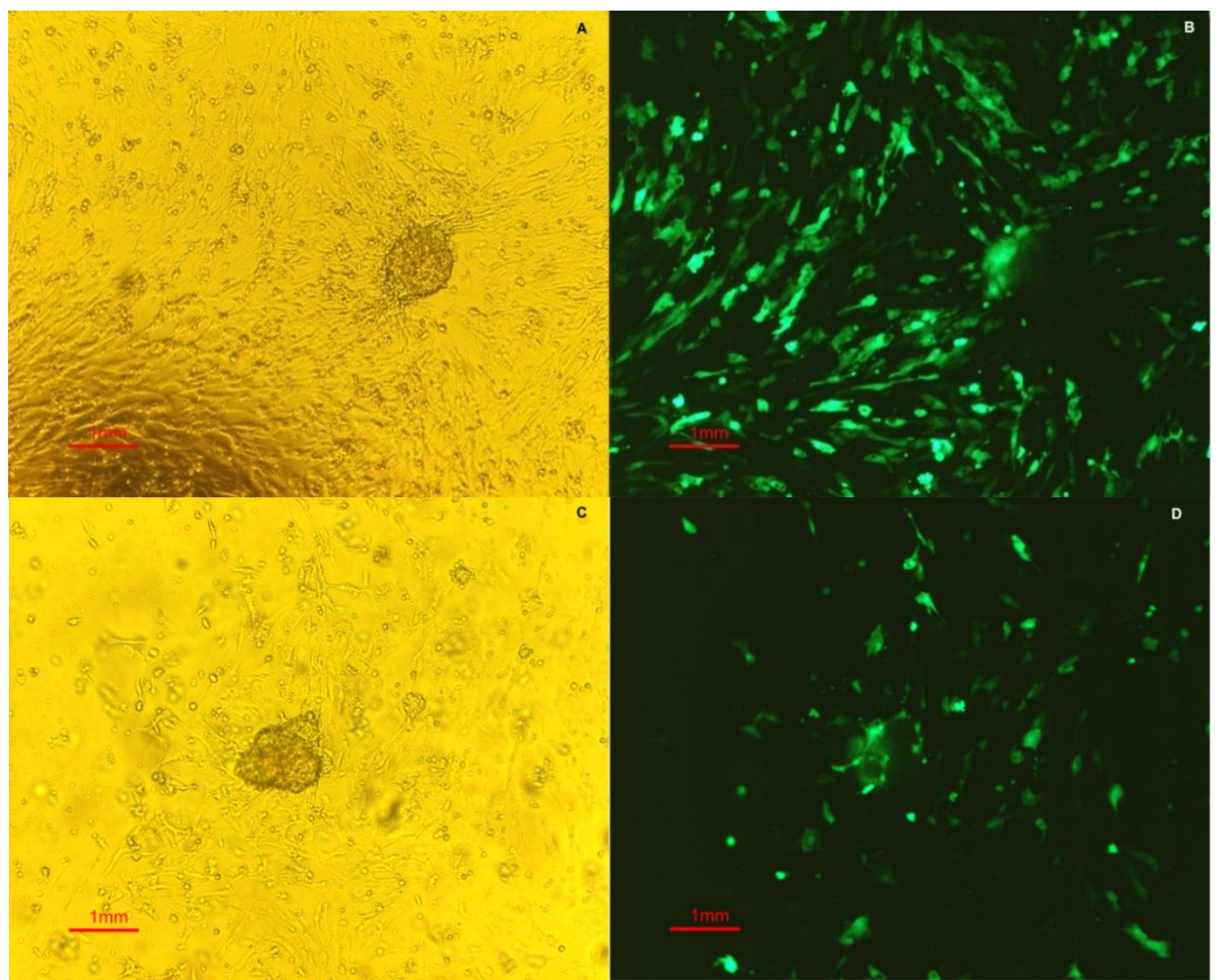

Figure 7 Transfection of spermatogonial stem cells: A) and B) Spermatogonial stem cells transfected with X-tremeGENE $\mathrm{HP}$ and the same cells fluorescing under UV light, respectively; C) and D) Spermatogonial stem cells transfected with Turbofect and the same cells fluorescing under ultraviolet light, respectively

The culture protocol employed in this study was developed with the aim of providing bovine SSCs with an optimized culture condition in which the cells would survive better and proliferate. Since, it is well known that antioxidants can inhibit apoptosis (Moreira et al., 2010), various concentrations of vitamin C and Trolox, alone and in combination, on the medium of SSCs were evaluated. The results indicated that individually distinct concentrations of vitamin $\mathrm{C}$ and Trolox could improve cell viability and the expression of pro- and anti-apoptotic genes (bax and bcl2. However, simultaneous use of these vitamins in the culture had a negative synergistic effect on their action.

It may not always be true that more antioxidants in the culture would proportionately increase antioxidant capacity (Cao \& Culter, 1993). The desirable performance of antioxidants takes place at a specific concentration and duration, to the extent that inappropriate doses or a short course of treatment may even culminate in the opposite effect (Kushki et al., 2015), because ROS in low concentrations can serve as key signal molecules in physiological processes and it is necessary to maintain appropriate ROS levels in SSC culture media (Wang et al., 2014). For instance, Trolox, at high concentration, acts like an oxidant instead of an antioxidant, and may even cause harmful effects (Cao \& Culter, 1993). Likewise, the highest concentration of vitamin $\mathrm{C}$ is cytotoxic, and leads to the generation of free radicals and pro-oxidative effects, which could end up with inhibition of proliferation or apoptosis (Wang et al., 2014). In other words, in spite of the undeniable advantages of antioxidants, in using a combination of vitamins in culture, the dosage and combination of each vitamin should be selected cautiously, because excessive amounts of antioxidants may act paradoxically to damage cells (Agarwal et al., 2004).

The combined use of vitamins $C$ and Trolox in current study was not as effective as their individual use, maybe owing to high concentrations of vitamins in the culture, as a result, unbalancing the concentrations between reactive oxygen species and antioxidants. This finding is in agreement with the study of Agarwal et al. (2004) and Hughes et al. (1998), who reported DNA damage after supplementing 
culture with high concentration of ascorbic acid and alpha tocopherol. Therefore, in using these vitamins together, more studies are needed to determine exact effective dosages and durations of antioxidants.

Wang et al. (2014) showed that supplementing culture with the proper concentration of vitamin C can protect cells against the damaging effects of ROS by suppressing ROS production and promote stem cell proliferation, regulating the expression of apoptosis-related genes. In fact, vitamin $C$ inhibits pro-apoptotic signals and activates anti-apoptotic signals in vitro (Hu et al., 2012). On the other hand, vitamin $\mathrm{E}$, which is known as a natural antioxidant, reacts with soluble free radicals in lipid membranes and prevents the process of lipid peroxidation by scavenging reactive oxygen species before they can cause damage to the cells (Moreira et al., 2010). According to Aliakbari et al. (2016), using a-tocopherol as a lipid soluble antioxidant not only increased SSCs viability up to $70-80 \%$, but the apoptotic rates of cells were decreased. In addition, analysing the expression of $\mathrm{Bax}$ and $\mathrm{Bcl} 2$ genes after supplementing culture with antioxidants revealed a falling apoptosis rate (Aliakbari et al., 2016).

For some time, transfecting primary cells has been considered a challenging and problematic matter (Gresch et al., 2004). Many effective and prevalent procedures for transfecting cell lines were not suited to transfecting these primary cell types efficiently (Hamm et al., 2002). The reason may be that typical transfection approaches are highly reliant on cell division. They transfer the DNA into the cytoplasm only by passing it through the cell membrane, and transfection would not complete until the disintegration of nuclear envelope during cell division (Hamm et al., 2002). Consequently, it is of paramount importance to take into consideration that any developed or new method must be independent of cell division because most primary cells divide at a relatively slow rate or sometimes they never divide at all (Hamm et al., 2002).

Hamm et al. (2002) and Gresch et al. (2004) successfully transfected primary cells using nucleofection as a new transfection technology. Hamm et al. (2002) transfected four human primary cell types with GFP, and reported that the transfection efficiency was between $28.9 \%$ and $45.3 \%$. Gresch et al. (2004) transfected 10 human primary cell types with EGFP or H2Kk, and the transfection efficiency of cells ranged from $35.71 \%$ to $66.39 \%$.

In the current study, in order to introduce a highly efficient approach for transfecting bovine primary SSCs in an optimized transfection condition, X-tremeGENE HP and Turbofect, as transfection reagents, were utilized in the presence of optimal concentrations of vitamin $\mathrm{C}$ and Trolox. Based on the findings of this study, a highly efficient gene transfer was obtained using X-tremeGENE HP $(\approx 70 \%)$, which was higher than results reported by Hamm et al. (2002) and Gresch et al. (2004).

\section{Conclusions}

In conclusion, the findings of this study demonstrated that antioxidants at an optimal dosage are able to inhibit apoptotic signals, activate anti-apoptotic signals, and increase SSC viability and population. There is broad consensus that antioxidants can prevent SSCs from damaging the cellular structure and apoptosis by decreasing the level of oxidative stress, which are their innate and well-known characteristics. Additionally, a high transfection efficiency of bovine primary SSCs was acquired by using X-tremeGENE HP as a novel and effective reagent for transferring foreign genes into primary SSCs, which are considered hard-to-transfect cells.

\section{Acknowledgements}

The authors would like to thank Dr. Khosro Hoseini Pajooh for helpful comments during the research. The authors are all grateful to Agricultural Institute of IROST for providing this project with laboratory facilities and other technical support. Part of this project was supported by Iran National Science Foundation (Grant No. 93015593).

\section{Authors' Contribution}

This project was designed by MZ. Taking samples, laboratory work and data collection was carried out by AJ and MZ. Statistical analysis has been done by AJ, MZ and MA. AJ was responsible for drafting the manuscript. MA and MZ analysed and interpreted the results and MRS and NEK as the project's advisors assisted and revised the results and manuscripts.

\section{Conflict of Interest Declaration}

The authors declare that they have no conflict of interest.

\section{References}

Agarwal, A., Nallella, K.P., Allamaneni, S.R. \& Said, T.M., 2004. Role of antioxidant in treatment of male infertility: An overview of the literature. Reprod. Biomed. Online 8, 616-627.

Aliakbari, F., Gilanib, M.A.S., Yazdekhastia, H., Korujif, M., Asgarig, M.R., Baazmd, M., Izadyar, F., Nejada, E.K., Khanezada, M. \& Abbasi, M., 2016. Effects of antioxidants, catalase and a-tocopherol on cell viability and oxidative stress variables in frozen-thawed mice spermatogonial stem cells. Artif. Cells Nanomed. Biotechnol. 45, 63-68. 
Aliakbari, F., Sedighi Gilani, M.A., Amidi, F., Baazm, M., Korouji, M., Izadyar, F., Yazdekhasti, H. \& Abbasi, M., 2016. Improving the efficacy of cryopreservation of spermatogonia stem cells by antioxidant supplements. Cellular Reprogramming 18, 87-95.

Aponte, P.M., 2009. Spermatogonial stem cells in the bull. PhD thesis, University of Utrecht, Netherlands.

Aponte, P.M. \& de Rooij D.G., 2008. Biomanipulation of bovine spermatogonial stem cells. Anim. Reprod. 5, 16-22.

Cao, G. \& Cutler, R.G., 1993. High concentrations of antioxidants may not improve defense against oxidative stress. Arch. Gerontol. Geriatr. 17, 189-201.

Chandar, N. \& Viselli. S., 2010. Lippincott Illustrated Reviews: Cell and molecular biology. R.A. Harvey (ed). Lippincott Williams \& Wilkins, Philadelphia. pp. 248.

Gordon, J.W., Scangos, G.A., Plotkin, D.J., Barbosa, J.A. \& Ruddle, F.H. 1980., Genetic transformation of mouse embryos by microinjection of purified DNA. Proc. Natl. Acad. Sci. USA. 77, 7380-7384.

Gresch, O., Engel, FB., Nesic, D., Tran, T.T., England, H.M., Hickman, E.S., Körner, I., Gan, L., Chen, S., CastroObregon, S., Hammermann, R., Wolf, J., Müller-Hartmann, H., Nix, M., Siebenkotten, G., Kraus, G. \& Lun, K., 2004. New non-viral method for gene transfer into primary cells. Methods. 33, 151-63.

Hamm, A., Krott, N., Breibach, I., Blindt, R. \& Bosserhoff, A.K., 2002. Efficient transfection method for primary cells. Tissue Eng. 8, 235-245.

Hu, J., Cheng, D., Gao, X., Bao, J., Ma, X. \& Wang, H., 2012. Vitamin C enhances the in vitro development of porcine pre-implantation embryos by reducing oxidative stress. Reprod. Domest. Anim. 47, 873-879.

Hughes, C.M., Lewis, S.E., McKelvey-Martin, V.J. \& Thompson, W., 1998. The effects of antioxidant supplementation during Percoll preparation on human sperm DNA integrity. Hum. Reprod. 13, 1240-1247.

Iannolo, G., Conticello, C., Memeo, L.D. \& Maria, R., 2008. Apoptosis in normal and cancer stem cells. Crit. Rev. Oncol. Hematol. 66, 42-51.

Izadyar, F., Spierenberg, G.T., Creemers, L.B., den Ouden, K. \& de Rooij, D.G., 2002. Isolation and purification of type A spermatogonia from the bovine testis. Reprod. 124, 85-94.

Kim, J.H., Jung-Ha, H.S., Lee, H.T. \& Chung, K.S., 1997. Development of a positive method for male stem cell-mediated gene transfer in mouse and pig. Mol. Reprod. Dev. 46, 515-526.

Kushki, D., Azarnia, M. \& Gholami, M.R., 2015. Antioxidant effects of selenium on seminiferous tubules of immature mice testis. Zahedan J. Res. Med. Sci. 17, 29-33.

Li, Y.F., Guo, Y.L., Li, X.H., Jin, F.S. \& Sun, Z.Y., 2005. Long-term survival of human spermatogonia stem cells in vitro and its functional identification. Natl. J. Androl. 11, 886-894.

Liu, S., Tang, Z., Xiong, T. \& Tang, W., 2011. Isolation and characterization of human spermatogonial stem cells. Reprod. Biol. Endocrinol. 9, 1-9.

Miao, Xiangyang, 2011. Production of transgenic animals using spermatogonial stem cells. Agr. Sci. China. 10, $762-768$.

Moreira da Silva, F., Marques, A. \& Chaveiro, A., 2010. Reactive oxygen species: A double-edged sword in reproduction. Open Vet. Sci. 4, 127-133.

Mosmann, T.,1983. Rapid colorimetric assay for cellular growth and survival: application to proliferation and cytotoxicity assays. J. Immunol. Methods 65, 55-63.

Nagano, M., Avarbock, M.R., Leonida, E.B., Brinster, C.J. \& Brinster, R.L., 1998. Culture of mouse spermatogonial stem cells. Tissue Cell 30, 389-397.

Niu, Y. \& Liang, S., 2008. Progress in gene transfer by germ cells in mammals. J. Genet. Genomics 35,701-714.

Olive, V. \& Cuzin, F. 2005. The spermatogonial stem cell: From basic knowledge to transgenic technology. Int. J. Biochem. Cell Biol. 37, 246-250.

Shi, L., Zhao, H., Ren, Y., Yao, X., Song, R. \& Yue, W., 2014. Effects of different levels of dietary selenium on the proliferation of spermatogonial stem cells and antioxidant status in testis of roosters. Anim. Reprod. Sci. 149, 103356.

Van Pelt, A., Morena, A., van Dissel-Emiliani, F., Boitani, C., Gaemers, I., de Rooij, D.G. \& Stefanini, M., 1996. Isolation of the synchronized A spermatogonia from adult vitamin A: Deficient rat testes. Biol. Reprod. 55, 439-44.

Wang, J., Cao, H., Xue, X., Fan, C., Fang, F., Zhou, J., Zhang, Y. \& Zhang, X., 2014. Effect of vitamin C on growth of caprine spermatogonial stem cells in vitro. Theriogenology 81, 545-555. 